\title{
A LITERATURA ALEMÃ DE WOLFGANG MENZEL, RESENHADA POR HEINRICH HEINE: TRADUÇÃO COMENTADA
}

\author{
THE GERMAN LITERATURE BY WOLFGANG MENZEL, REVIEWED BY \\ HEINRICH HEINE: A COMMENTED TRANSLATION
}

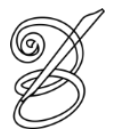 \\ Felipe Vale da SILVA* \\ Universidade de São Paulo
}

\begin{abstract}
Resumo: Die deutsche Literatur von Wolfgang Menzel (1828) não é apenas uma das resenhas mais conhecidas de Heinrich Heine, mas também um importante documento sobre a cultura alemã em sua fase de transição do romantismo para a literatura da Jovem Alemanha (Junges Deutschland). O presente artigo, além de trazer a tradução integral do texto em questão, faz uma leitura que visa a evidenciar as principais tensões vividas por escritores naquele momento de assumida estagnação cultural e censura política. Heine se vale do registro da resenha para propor um programa estético inovador, e o faz declarando o final do Período da Arte (Kunstperiode) representado por Johann Wolfgang von Goethe e os teóricos do romantismo.

Palavras-chave: Heinrich Heine. Jovem Alemanha. Recepção de Goethe. Wolfgang Menzel.
\end{abstract}

Abstract: Die deutsche Literatur von Wolfgang Menzel (1828) is not only one of Heinrich Heine's most renowned reviews but also an important document about German culture in its transition phase from romanticism to the literature of the Young Germany (Junges Deutschland). This article consists both in a translation of the aforementioned text and aims at shedding some light on the main issues faced by writers in that moment of assumed cultural stagnation and political censorship. Heine employs the genre of the review so as to propose an innovative aesthetical program, and does so by declaring the end of the Period of Art (Kunstperiode) represented by Johann Wolfgang von Goethe and the theoreticians of Romanticism.

Keywords: Heinrich Heine. Junges Deutschland. Reception of Goethe. Wolfgang Menzel.

\section{Heine, Menzel e a crise da literatura na era Metternich}

Esta é a época dos pequenos!

$\mathrm{O}$ mundo demanda grandes feitos

de gente pequena $[\ldots]$

- Karl Immermann em Tulifäntchen (1832)

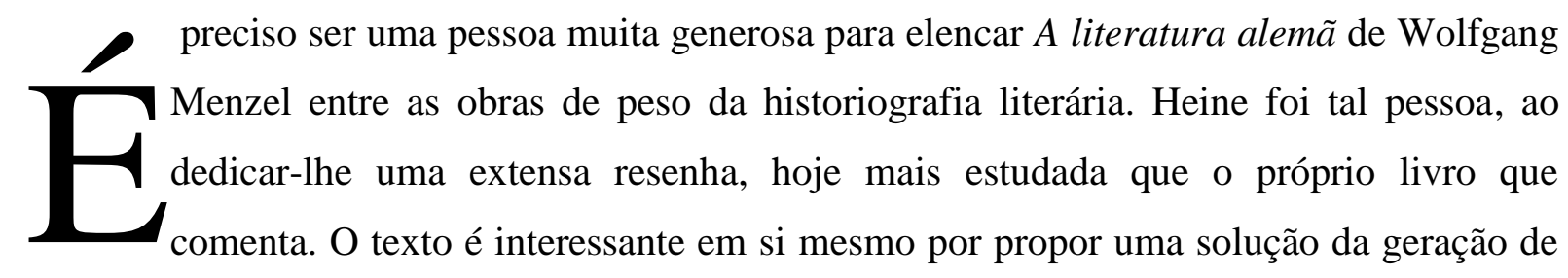

1820 contra a estagnação da cultura alemã na Era Metternich, época em que todos os ousados

SILVA. A literatura alemã de Wolfgang Menzel, resenhada por Heinrich Heine: tradução comentada. Belas Infiéis, v. 6, n. 2, p. 177-197, 2017. 
o bastante para criticar a situação nacional foram sistematicamente caçados como “demagogos" ou "bonapartistas" (KOPELEW, 1981, p. 88).

Aquela foi uma época de retomada de um equilíbrio perdido, e isso em diversos sentidos. A Europa acabara de sustar a política expansionista de Napoleão Bonaparte e seus representantes se reuniram para decidir os rumos do continente no famoso Congresso de Viena, de 1814 a 1815. No evento, o chanceler austríaco Klemens von Metternich teve uma atuação marcante, algo que contribuiu para sua fama, garantindo sua influência duradoura sobre toda a Confederação Alemã por quase meio século. Na dita Era Metternich, conservadorismo e nacionalismo eram as palavras de ordem, e marcas indubitáveis de um novo período menos afeito a ideias inovadoras e ousadas se deixavam sentir por jovens artistas como Heine. Também a onipresença dos grandes nomes da era anterior passava a inibir a renovação da cena literária; Goethe, Schiller e os irmãos Schlegel, apesar de suas importantes contribuições, tornavam-se uma barreira para que algo novo, relacionado à realidade dos anos 1820, surgisse e recebesse a devida atenção.

Por fim, estudar o histórico das relações entre Menzel e seus contemporâneos nos abre

um quadro dramático de lealdades divididas e traições pessoais que definiram a história literária alemã por duas décadas. ${ }^{\text {ii }}$ Wolfgang Menzel ficou para a história cultural como agente do atraso, um dos responsáveis pela proibição das obras de virtualmente todos os grandes autores da Jovem Alemanha em dezembro de 1835. Esse é um desdobramento surpreendente se voltarmos alguns anos e constatarmos o início da carreira pública de Menzel como membro engajado de ligas estudantis, atuante no jornalismo liberal no período prévio à Revolução de $1830^{\mathrm{iii}}$, para, só mais tarde, ocupar um cargo oficial em Württemberg e atuar como figura chave em um processo de censura literária sob as graças do governo Metternich. Um de seus antigos companheiros foi Karl Gutzkow, que como porta-voz do movimento Jovem Alemanha comenta o ocorrido nos seguintes termos:

Em 1834 [um ano antes da mencionada proibição ser efetivada], a assembleia do Alto Parlamento em Frankfurt am Main não tinha nada na cabeça além de Giovine Italia e Carbonari [sic, Carboneria] e Vendetta e Munkács e Spielberg, e outros reconsideraram a descoberta que supostamente fizeram de uma Giovine Alemagna de literatos [...] Em suma, quis-se aceitar como definitivo e seguro que cinco escritores - aos quais se agregou um sexto voluntário, Gustav Kühne — seguiam o programa que Wolfgang Menzel lhes imputou: francesismo, emancipação carnal, ateísmo, etc, foram alguns dos termos discutidos em uma sessão noturna (GUTZKOW, 1873, p. 1). ${ }^{\text {iv }}$ 
O contexto da cena ilustrada acima é a dieta de Frankfurt, uma assembleia em que os representantes dos trinta e nove estados da Confederação Germânica se reuniam. $\mathrm{O}$ ano de 1834 é marcado por perseguição a grupos insurrecionais como as mencionadas Giovine Italia e Carboneria - a ironia é que estes grupos constituíram movimentos políticos organizados, capazes de mobilizar ações militares e golpes de Estado. Imaginar que um punhado de jovens escritores poderia ser comparado a tais organizações, sobretudo em sua capacidade de oferecer perigo real ao governo, era fruto de uma paranoia generalizada e, como Gutzkow notou desde o início, das maquinações de Wolfgang Menzel. Este se valeu de sua posição privilegiada na assembleia do Estado para promover seu próprio programa liberal-nacionalista e livrar-se de seus competidores políticos - mesmo aqueles que tinham ideias afins às suas. Os ataques em questão, portanto, são tanto expressão de preferências ideológicas quando resultado de uma estratégia do homem para afastar seus principais antagonistas do mercado literário (HOHENDAHL, 1988, p. 185). Para tal, Heine era acusado de ateísmo e galofilia, Gutzkow de escrever um romance pornográfico e assim por diante, tudo por meio de argumentos ad hominem que, em frente a uma assembleia retrógrada da era Metternich, soavam bastante razoáveis. ${ }^{\vee}$

Todos esses são desdobramentos inesperados de algo que começou como uma parceria. Em 1828, Heinrich Heine publicou a resenha sobre A literatura alemã, o livro mais ambicioso do primeiro Wolfgang Menzel, em um momento em que eram colegas de trabalho. A época já estava saturada de compêndios sobre a literatura alemã para fins pedagógicos, que basicamente consistiam em um agrupamento de nomes, características estereotipadas de certos autores e escolas literárias, sem qualquer tentativa de sistematizar e refletir a situação da cultura contemporânea. Aqui encontramos o principal diferencial da obra em questão: ela ao menos trata a literatura alemã da perspectiva de 1828 , e questiona a utilidade do Classicismo de Weimar e do Romantismo para aquela nova era de radicalização política (ver GUTZKOW, 1873, p. 1; HÖHN, 2004, p. 224-225). "Menzel busca conceituar a relação da vida com livros e descobrir uma organicidade no mundo dos textos", Heine afirma em determinado trecho, ressaltando como virtude do colega "uma busca por cientificidade, o que é igualmente uma tendência de nosso tempo moderno, uma dessas tendências que o diferencia do Período da Arte anterior". vi

Aqui temos a primeira menção ao Período da Arte (Kunstperiode), conceito central da historiografia literária do século XIX: trata-se de um período de grandes realizações em que, 
pela primeira vez, o resto do mundo lê e discute a literatura dos alemães. Ele se localiza entre o surgimento do Sturm und Drang nos anos 1770 e a fase madura de Goethe, época da qual Heine escreve e em que, implicitamente, identifica um certo ar de decadência. A ideia de que o Período da Arte chegava ao estado de declínio só se intensificou na virada para a década de 1830, quando seus maiores representantes faleceram. Goethe, Schleiermacher, Rahel Varnhagen von Ense, Friedrich Schlegel, Hegel, Wilhelm von Humboldt foram, um por um, ceifados pela idade ou por doenças, de forma que apenas imitadores baratos de suas estéticas (segundo Menzel e Heine) restaram. Sobretudo a morte de Goethe, situada pouco após as revoluções de 1830, foi sentida como "símbolo de um recomeço na literatura, que prometia a democratização de temas e estéticas, assim como a libertação da esfera pública, a liberdade de expressão e imprensa, e o banimento da censura". vii

É uma provocação clara por parte de Heine e Menzel propor um conceito tão abrangente, que abarca manifestações literárias díspares como produto de uma só configuração histórica. Pouquíssimos historiadores atuais aceitariam colocar Goethe ao lado dos românticos de Heidelberg, por exemplo, mas entendamos tal asserção como uma manobra 180 argumentativa. Criar o conceito de Período da Arte implica relegar as produções literárias de toda uma geração ao passado, reduzi-las a monumentos inertes (LAUSTER, 2005, p. 189). Para tal, Heine acentua aquilo que clássicos e românticos têm em comum — a chamada Kunstidee ou "ideia da arte" — justamente para declarar seus interesses como jovem escritor. Por "ideia da arte" Heine entende o princípio esteticista ao qual a antiga geração de artistas alemães recorreu uma vez que cresceu e se formou em um império antiquado, que lhes negava qualquer possibilidade de participação política. Essa concepção caracteriza-se pelo alheamento a questões públicas, pelo refúgio em ideias platônicas de beleza e sublimidade que não teriam mais espaço naquela nova era de urgências revolucionárias. "Agora os interesses mais elevados da própria vida estão valendo, a Revolução invadirá a literatura", lemos em sua carta a Varnhagen von Ense de 04/02/1830. ${ }^{\text {viii }}$

"O núcleo do livro de Menzel não é mais a ideia da arte", ix diz o início da resenha, e aqui Heine encontra um aliado em quem possa se ancorar e desenvolver as próprias ideias. $\mathrm{Na}$ verdade, ele se aproveita de uma ideia superficialmente desenvolvida no livro do amigo para acrescentar argumentos que se tornarão cruciais para a Jovem Alemanha. Heine, e não Menzel, é a fonte de juízos que reconhecemos como formativos da identidade literária da geração. Suas contribuições para o método historiográfico são inestimáveis e podem ser 
entendidas a partir daquilo que elogia no livro menos expressivo de Menzel. Em ambos, a recepção de uma obra é frequentemente tomada como ponto de partida de sua crítica. ${ }^{\mathrm{x}}$ Produtos literários são entendidos como parte da superestrutura, para então serem aliados a determinadas correntes de pensamento que constituem as forças socioculturais atuantes em cada época. Assim, Heine reverte a ordem das análises dos estudos literários na era do romantismo, uma que buscava significados imanentes em cada obra de ficção, para alçá-las a um panorama histórico concreto. Essa é uma marca que ficará em toda sua obra posterior de historiografia cultural, da qual se destacam Contribuição a História da Religião e da Filosofia na Alemanha (1833) e A Escola Romântica (1836). ${ }^{\mathrm{xi}}$

Suas avaliações de autores românticos são unilaterais, é certo, e não fazem jus a todas as nuances desse movimento complexo. Há um descompasso enorme entre aquilo que Heine escreveu em seus diagnósticos de época e sua própria produção literária. Em muitos poemas de Livro das Canções (escritos entre 1817 e 1826) ele soa como um continuador da escola romântica. Suas técnicas de argumentação e de escrita, igualmente, são afins a ela, ao ponto de um importante historiador literário dos anos 1840, Robert Prutz, reduzir Heine e o resto da Jovem Alemanha a românticos que vieram ao mundo tarde demais, e que, pior ainda, não tinham tato o suficiente para reconhecê-lo. ${ }^{\text {xii }}$ Hohendahl $(1988$, p. 194) chega a afirmar que "[a] Jovem Alemanha ofereceu a oposição mais decidida e declarada dos romantismos precedentes, mas de um modo essencialmente romântico. Ela quis estreitar a brecha entre literatura e vida, mas para tal, valeu-se de meios exclusivamente literários". xiii

Esse argumento é reducionista, uma vez que desconsidera tanto a história social da era Metternich, quanto as contribuições de Heine para o método dialético de análise literária posterior. Comecemos pelo último aspecto, retraçando por um instante a argumentação presente na resenha em questão: “a crise do paradigma goetheano e romântico deu-se por sua inabilidade de abarcar o momento dialético da história no sentido essencial da palavra, isto é, como um diálogo com o presente". ${ }^{\text {iv }}$ Em sua resenha, Heine criticou Menzel justamente por querer se livrar de vez de Goethe, como se este não houvesse escrito uma única palavra e exercido uma influência irreversível na cultura global (ver HEINE, 1828, p. 295 et seq). Em outras palavras, Menzel fracassou em sua análise no momento em que deixava de ser rigorosamente dialético e se esquecia de um dado primordial: todo historiador deve subordinar-se a fatos elementares que constituem a história da literatura, da cultura, da política etc. E Goethe é um fato consumado. A questão de alguém que vivia em 1828 era 
saber apropriar-se criticamente das contribuições feitas por autores mais antigos, para então identificar o momento em que - e motivo pelo qual - um ou outro aspecto deles deveriam ser superados. Por isso Heine (1828, p. 298) insiste:

Não podemos deixar de observar expressivamente que não entendemos por Goethenthum as obras de Goethe, aquelas caras criações que talvez ainda sobreviverão quando a língua alemã já estiver há muito morta. Pela palavra Goethenthum referimo-nos acima, ao contrário, às formas goetheanas, como as encontramos moldadas por discípulos, e ao apitar frouxo da melodia que o velho assoviava. ${ }^{\mathrm{xv}}$

Isso significa: Goethe tornou-se um protótipo de uma visão de mundo, que vive tanto em seus seguidores mais talentosos quanto em seus imitadores menos enérgicos. Quem o conheceu em meados de 1770, quando escreveu obras no melhor espírito crítico do Sturm und Drang como Götz von Berlichingen e Os sofrimentos do jovem Werther, mal poderia reconhecê-lo em sua velhice. O momento definitivo do declínio da dita escola de Goethe, argumenta Heine, deu-se em 1813, quando o velho poeta se envolveu em um debate público totalmente desnecessário contra os românticos e ajudou a dividir a literatura alemã ainda mais em grupos antagônicos. Esse debate foi iniciado com o artigo A nova arte patriótico-religiosa alemã de Heinrich Meyer, que acusava categoricamente a identidade artística romântica de ser subproduto de uma cultura místico-cristã, desvinculado da grande herança artística que começava com os gregos arcaicos, passava pela Renascença e chegava ao século XIX de forma diluída. Supostamente no Classicismo de Weimar. O artigo de Meyer foi publicado no segundo caderno da revista Sobre Arte e Antiguidade nas regiões do Reno e do Meno, editada por Goethe em 1817, e por algum motivo foi incluído no vigésimo volume das obras completas do velho poeta, aquela que hoje chamamos edição de Berlim. ${ }^{\text {xvi }}$ Por esse motivo, Heine provavelmente conhecia o artigo como uma conclusão da obra de seu antigo mestre, e não como um panfleto polêmico do menos conhecido Meyer.

O espanto de Heine é razoável: a Europa acabava de sair da Era Napoleônica e, com o Congresso de Viena de 1814/5, estava à beira de perder conquistas importantíssimas feitas desde a Revolução Francesa. As monarquias absolutistas voltavam a atuar com direitos plenos de intervenção militar; a liberdade de expressão e de imprensa desapareciam num piscar de olhos. Para Heine, de agora em diante, seria impossível assumir um cargo público significativo unicamente pelo fato de ser judeu (KOPELEW, 1981, p. 46). E ainda assim, a edição de verão do Sobre Arte e Antiguidade parecia dizer: Goethe estava preocupado em 
coroar-se como rei dos literatos. Esse foi o fim da picada para o jovem Heinrich, que comenta em A Escola Romântica (HEINE, 1836, p. 72): “Com esse artigo, Goethe executou também seu $18^{\circ}$ Brumário na literatura alemã”xvii — assim como Napoleão dissolveu a Revolução Francesa em 1799 e declarou-se cônsul supremo da França. E depois, imperador vitalício. Já na resenha sobre Menzel encontramos um desdobramento dessa metáfora do golpe de Estado goetheano contra o pequeno reinado dos românticos, e menção da profunda animosidade que se instalou em meio aos intelectuais a partir daí. Além disso, encontramos espelhada a convicção da Jovem Alemanha de que uma nova literatura podia lidar com questões um pouco mais sérias.

Se as relações de Heine com Goethe permaneceram ambivalentes até o fim de sua vida (DREWITZ, 1974, p. 118), isso se deve ao caráter dialético de seu pensamento. O mesmo ocorre quando pensamos na onipresença da ironia em sua ficção, uma ironia semelhante à que encontramos em Friedrich Schlegel e Ludwig Tieck. Para os românticos, a ironia era uma saída do impasse de um problema epistemológico insolúvel; para Heine, ela se tornou um meio de construção textual utilizado para propor saídas de impasses próprios do desenvolvimento histórico (parafraseando Ibid., p. 120). Mesmo a tal "ideia da arte" deixa marcas importantes para a construção da nova literatura. Só quando Moritz, Goethe e Schiller declararam a autonomia radical da expressão artística é que autoridades do Estado e da igreja perderam seu poder absoluto sobre a cultura. A consequência negativa dessa manobra foi a abertura de uma fenda crescente entre vida social e expressão criativa. "Assim que a esfera estética aparece removida dos reinos da política e moralidade, torna-se impossível designar à arte qualquer propósito específico além da autorreferencialidade", comenta Hohendahl (1988, p. 192). ${ }^{\text {xiii }} \mathrm{E}$ isso significava um rompimento com os objetivos mais sérios do Iluminismo.

O programa de Heine, da resenha sobre Menzel em diante, caracterizou-se por certa oscilação ora à ideia de autonomia, ora a preceitos de utilidade política da literatura. Ele desejava o fim da arte decorativa e inofensiva dos intelectuais alemães, mas temia que a tão desejada revolução trouxesse consigo a destruição da cultura. Em um devaneio pessimista de final de vida, ele chega a fantasiar com uma situação em que sua primeira coletânea de versos, o Livro das Canções, iria "servir de embrulho para o vendedor de temperos, para colocar café ou rapé para as velhas do futuro" (prefácio de Lutetia, 1855, citado por SAFRANSKI, 2010, p. 232). Habermas (1997, p. 94) resume bem o dilema enfrentado pelo poeta, talvez de forma mais representativa do que qualquer outro membro da Jovem Alemanha: 
Sob o ponto de vista do intelectual, arte e ciência permanecem certamente autônomas, mas não absolutamente esotéricas; para ele, é certo que a formação da vontade política relaciona-se com o sistema dominado pelos políticos de vocação, mas não é exclusivamente controlada por ele.

Essa era também a visão de Heine. Ele sempre defendeu a autonomia da arte e da literatura, sem fetichizá-las. [...] aquela independência, representada na obra de Goethe, do "segundo mundo", o mundo da manifestação estética; ela se opõe apenas à consequência quietista que os sectários de Goethe tiraram daí contra toda espécie de escritor engajado [...] Do mesmo modo se justificavam o horror e o espanto de Heine ante o futuro domínio dos iconoclastas, que então destruirão "com seus rudes punhos todas as figuras de mármore de meu amado mundo da arte".

Um desses iconoclastas era o próprio Menzel, que intentava livrar-se de Goethe e de toda a ideia da arte. Isso talvez tenha motivado Heine a dedicar-lhe uma resenha ao mesmo tempo elogiosa e irônica. Nela encontramos um documento histórico privilegiado para a compreensão dos desenvolvimentos da Jovem Alemanha até seu desmonte em 1835. Depois do fracasso de cada uma das revoluções que testemunhou, um Heine exilado abandonou aos poucos a poesia lírica para dedicar-se a uma modalidade de prosa que lhe é característica: uma mistura de relato de viagens, crítica social, filosofia e ficção narrativa. Esse método de escrita lhe possibilitaria desviar da censura (que proibiu boa parte de seus livros na Alemanha) e lidar com o problema da cisão entre arte e vida, proposto na resenha em questão.

Algo semelhante aconteceu na literatura de Börne: esses dois autores resolveram a crise da literatura no declínio do Período da Arte encurtando a lacuna entre literatura e crítica. Não como os românticos fizeram - poetizando o discurso crítico, mesclando as faculdades analíticas com jogos próprios da imaginação —, mas deixando que a ficção narrativa fosse permeada por elementos da crítica (parafraseando HOHENDAHL, 1988, p. 193). Mais uma vez, diferentemente do Romantismo, a Jovem Alemanha tinha um interesse de reconquistar o caráter público da crítica que havia se perdido quando os teóricos se entregaram a análises imanentistas de obras de arte como se elas fossem entidades exiladas do mundo das relações humanas (Ibid., p. 199). A arte literária passava a ser entendida como meio de reflexão dos mesmos problemas com os quais o jornalismo e discurso político lidam. Isso não torna Heine um romântico tardio, como Safranski (2010, p. 218-233) parece insistir, uma vez que nem sua concepção estética, nem sua visão de mundo eram românticas. Ele viveu um momento menos otimista do que a virada do século XVIII e encarou o problema da desproporção entre inspirações pessoais e realidade social de forma mais consciente, irônica e expressiva que qualquer escritor de sua época (HÖHN, 2004, p. 6). 
Por fim, o texto traduzido abaixo pode servir como porta de entrada não só para diversas questões cruciais relativas à Jovem Alemanha, como também para a fortuna crítica de Goethe e dos românticos. Ademais, a oscilação constante entre seriedade e sarcasmo fazem sua leitura valer por si só. A tradução foi feita a partir da primeira versão da resenha de 1828 , publicada no jornal Neue allgemeine politische Annalen (ver referências bibliográficas).

\section{Tradução: A literatura alemã, de Wolfgang Menzel. Segunda parte. Stuttgart: irmãos Frankh. 1828.}

"Saiba que toda a obra digna de ser publicada não pode encontrar quem a julgue no momento de sua publicação; ela deve primeiramente educar seu público, e então erigir uma cadeira de juiz para si ${ }^{\text {xix }}$ - Spinoza esperou mais de um século antes que uma palavra pertinente fosse dita a seu respeito. Possivelmente a primeira palavra pertinente sobre Leibniz ainda está para ser dita; no caso de Kant, isso é mais do que certo. Se um livro encontra um juiz competente no momento de sua publicação, temos aí prova suficiente de que seria um tanto melhor que ele não tivesse sido escrito."

Essas palavras são de Johann Gottlieb Fichte, e nós as tomaremos como lema prévio à resenha da obra de Menzel, em parte para insinuar que não ofereceremos nada além de sua resenha, em parte também para consolar seu autor caso nada aprofundado seja dito sobre o livro, mas discutamos somente sua relação com livros afins, assim como superficialidades e aspectos particularmente destacados.

Ao buscar detectar preliminarmente com quais livros disponíveis a obra em questão pode ser comparada, vêm-nos logo à memória as preleções de Friedrich Schlegel sobre literatura. Também esse livro não encontrou um juiz competente, e como em tempos recentes muitas vozes discordantes se levantaram com ímpeto contra Friedrich Schlegel por razões protestantes mesquinhas, ninguém ainda foi capaz de gerar uma avaliação desse grande avaliador. E mesmo se formos obrigados a admitir que seu irmão August Wilhelm tem um poder de penetração crítica superior (assim como alguns críticos recentes, por exemplo Willibald Alexis, Zimmermann, Varnhagen von Ense e Immermann), estes só nos deixaram monografias, enquanto Friedrich Schlegel captou com maestria a totalidade dos esforços intelectuais reunidos como quem reorienta suas manifestações de volta ao logos criador original da qual provieram, de modo que seu livro se iguala a uma criativa canção de espíritos. 
As bizantinices religiosas que permeiam os escritos tardios de Schlegel, e que só ele presumiu ser o primeiro a escrever, acabam sendo algo meramente acidental. Nas preleções sobre literatura, a ideia da arte ainda é o centro dominante (talvez mais do que ele próprio saiba), e constitui a trama de todo o livro com seus raios dourados. Porém, a ideia da arte é ao mesmo tempo o centro de toda aquela época da literatura que inicia com o surgimento de Goethe e só agora chegou a seu fim. Ela tem seu verdadeiro centro no próprio Goethe, o grande representante desse período - e se Friedrich Schlegel, em sua avaliação, comete o erro de negar a Goethe tal posição central, é por causa de um ressentimento perdoável. Dizemos "perdoável” para não empregar a palavra "humano": os Schlegels, guiados pela ideia da arte, reconheceram a objetividade como o requisito mais elevado de uma obra artística, e uma vez que a encontraram em alto grau em Goethe, tornaram-no um líder, reverenciado pela nova escola como rei. Enquanto foi rei, ele expressou sua gratidão como reis tratam de fazer, rejeitando os Schlegels com ofensas e pisoteando sua escola.

A Literatura Alemã de Menzel é uma obra paralela, digna dos trabalhos mencionados de Friedrich Schlegel. Ela traz a mesma grandiosidade na composição, no esforço, na firmeza 186 e em seus erros. Ambas as obras oferecerão aos literatos do futuro material para reflexão, não só na medida em que nelas são mencionadas as mais belas preciosidades intelectuais, mas também na medida em que cada uma dessas obras caracterizam o tempo em que foram escritas. Esta última circunstância também nos provê a maior parte do prazer quando comparamos as duas obras. Na de Schlegel vemos bem o esforço, as necessidades, os interesses, toda a disposição intelectual alemã da penúltima década, e a ideia da arte como centro do todo. Se as preleções de Schlegel, porém, constituem uma epopeia da literatura, a obra de Menzel parece-nos antes um drama atribulado. Os interesses da época entram em cena e proferem seus monólogos, temor e piedade são exprimidos, amigos aconselham, inimigos pressionam, os partidos se levantam em contraposição, e o autor faz jus a todos os lados como um dramaturgo autêntico, não tratando com qualquer predileção particular nenhum dos partidos em conflito. Caso sintamos falta de algo, é apenas do coro que expresse serenamente o significado último da batalha. Mas não poderíamos prover um tal coro ao senhor Menzel devido ao singelo fato de que ele ainda não viveu até o fim deste século. Pelo mesmo motivo, reconhecemos o núcleo autêntico de um livro de uma época anterior, o de Schlegel, com muito maior facilidade do que o de um livro do presente imediato. O que podemos constatar é que o núcleo do livro de Menzel não é mais a ideia da arte. Em vez disso, Menzel busca 
conceituar a relação da vida com livros e descobrir uma organicidade no mundo dos textos. Às vezes parece-nos que ele trata a literatura como vegetação - que nos acompanha por aí a coletar espécimes vegetais, dá os nomes às árvores, faz graça sobre os carvalhos mais altos, fareja comicamente cada canteiro de tulipas, beija cada uma das rosas, inclina-se sobre algumas das pequenas flores do prado, e mostra ser tão entendido que quase podemos crer que tenha a capacidade de ouvir a grama crescer.

Por outro lado, reconhecemos em Menzel uma busca por cientificidade, o que é igualmente uma tendência de nosso tempo moderno, uma dessas tendências que o diferencia do Período da Arte anterior. Fizemos grandes conquistas no campo da intelectualidade, e a ciência deverá assegurá-las como propriedade nossa. Até mesmo o governo de alguns estados alemães reconheceu o significado dessas conquistas, particularmente no caso da Prússia, onde nomes como Humboldt, Hegel, Bopp, A. W. Schlegel, Schleiermacher etc brilham com maior força nesse campo. Uma busca idêntica alastrou-se para a França, sobretudo por influência de tais intelectuais alemães. Também aqui [na França] reconhece-se que todo conhecimento tem um valor em si e por si próprio, que ele não deve ser cultivado em função da utilidade imediata, mas que, para encontrar seu lugar no reino do pensamento, deve ser transmitido para as gerações posteriores como o melhor de nossa herança.

O senhor Menzel é mais uma cabeça enciclopédica do que um cientista sintetizador. Mas já que sua vontade o impele para a cientificidade, encontramos em seu livro uma estranha união de sua disposição natural com sua busca previamente concebida. Os assuntos partem, por conseguinte, de um princípio mais interno e singular, mas são tratados individualmente a partir de um esquematismo espirituoso que, ainda assim, se complementa, de modo que o livro forma um conjunto bom e arredondado.

Nesse sentido talvez o livro tenha proveito para o grande público, facilitando-lhe a formação de uma visão geral sobre o assunto. Esse público encontrará em toda parte algo espirituoso, profundamente ponderado e atrativo, que não precisa ser relacionado apenas com um princípio último, mas que é plenamente válido em si e para si. De forma alguma falta gracejo (Witz) nos produtos intelectuais de Menzel, e temos todo o direito sair em busca dele. Ele parece até mais digno, pois em vez de flertar consigo mesmo, surge unicamente em prol do assunto - embora não se possa negar que o sr. Menzel frequentemente deve servir-se dele para preencher as lacunas de seu conhecimento. O sr. M. é, sem dúvida, um dos escritores mais chistosos (witzig) na Alemanha; ele não pode negar a sua natureza, e mesmo se quisesse, 
contra todas as incidências do humor, pregar por aí em um tom rígido e emperucado, logo seria surpreendido por gracejo mental (Ideenwitz). Esse tipo de gracejo (Witzart), uma associação de pensamentos nunca antes formada em uma cabeça humana, a coabitação selvagem entre piada e sabedoria, é predominante na obra de Menzel. Mais uma vez elogiamos o bom humor (Witz) do autor, ainda mais porque há muitas pessoas chochas no mundo que gostariam de banir o humor. Todos os dias pode-se ouvir um pantaleão que trata de afervorar-se contra essa força anímica mais baixa, o humor, e, sendo um bom cidadão e pai de família, pede à polícia que o proíba. Mesmo que o humor pertença às forças anímicas mais baixas, cremos que ele não é de todo mau. Ao menos não gostaríamos de passar sem ele. Desde que já não é mais costume portar uma espada ao lado do corpo, tornou-se absolutamente necessário que tragamos humor na cabeça. E, além disso, caso sejamos carrancudos o bastante para nos valer dele não só como uma defesa natural, mas até mesmo como arma de assalto, os senhores, nobres pantaleões da pátria alemã, deixariam de esquentar tanto a cabeça! Aquele humor agressivo (Angriffswitz) que os senhores chamam sátira tem um bom uso nesta época má, imprestável. Nenhuma religião mais é capaz de conter o desejo de pequenos governantes da terra. Eles ofendem a vós com impunidade e seus cavalos pisoteiam vossas colheitas. Vossas filhas passam fome e vendem suas virgindades ao novo-rico imundo; todas as rosas deste mundo são a presa de uma estirpe suspeita de acionistas e paus-mandados cheios de privilégios, e não há nada que vos protegerá da insolência da riqueza e do poder - a não ser a morte e a sátira.

"A universalidade é o caráter de nosso tempo", diz o senhor Menzel em sua obra, na segunda parte da p. 63, e já que ela, como mencionado acima, traz o caráter de nosso tempo, encontramos aí também uma busca pela universalidade. Daí advém uma expansão para todas as direções da vida e do conhecimento, expressas sob os seguintes títulos de capítulos: "A dimensão da literatura, Nacionalidade, A influência da erudição escolar, A influência da literatura estrangeira, O comércio literário, Religião, Filosofia, História, Estado, Educação, Natureza, Arte e Crítica." É de se duvidar que um jovem estudioso possa ser iniciado em todas as disciplinas existentes tão profundamente que tenhamos a permissão de esperar dele uma crítica fundamentada dos acontecimentos mais recentes. O senhor Menzel soube auxiliarse por meio de divinação e invenção. Geralmente ele é feliz em suas divinações; em suas invenções, ele é sempre espirituoso. Embora suas suposições sejam por vezes arbitrárias e equivocadas, ele é insuperável na compilação dos elementos homogêneos e opostos. Ele 
procede de modo combinatório e conciliatório. Tendo em conta o objetivo dessas páginas, gostaríamos de transmitir o trecho seguinte, do capítulo "Estado", como uma mostra do método descritivo de Menzel:

“Antes de considerarmos a literatura da prática política, voltaremos nossos olhares para as teorias. Toda a prática parte da teoria. Já não é mais época de os povos entrarem em desacordos passageiros decorrentes de certa insolência sensual, ou por motivos ocasionais e locais. Em vez disso, eles lutam por ideias, e por isso mesmo sua luta é uma luta universal, interna ao próprio seio de cada povo, e apenas na medida em que ela é a luta de um povo contra o outro, este afirma sua preponderância sobre o outro através da dita ideia. A batalha tornou-se inteiramente filosófica, assim como outrora foi religiosa. Não é por uma terra pátria ou por um grande homem que se luta, mas por convicções às quais tanto um povo quanto seus heróis devem submeter-se. Os povos venceram com ideias, mas tão logo ousam colocar seu nome no lugar delas, envergonham-se. Os heróis conquistaram um tipo de domínio sobre o mundo através de ideias, mas tão logo eles as deixam de lado, desfazem-se em pó. Os seres humanos mudaram; apenas as ideias persistiram. Nossa história não foi nada além de uma escola de princípios. O século passado foi mais rico em especulações antecipadoras; o presente é mais rico em contemplação e preceitos retirados da experiência. Em ambos encontra-se a alavanca dos acontecimentos por meio da qual tudo o que aconteceu se deixa explicar."

"Há apenas dois princípios ou polos opostos no mundo político, e em ambas as extremidades do grande eixo repousam partidos, e eles entrechocam-se com exacerbação crescente. Ainda que nenhum emblema de partido tenha o mesmo valor para cada um de seus adeptos; ainda que muitos mal tenham noção de pertencer a esse partido em particular; ainda que os membros de um partido lutem entre si uma vez que derivam conclusões diferentes de um e mesmo princípio; em geral, o crítico mais sutil, assim como o público-leitor de jornais como um todo, deve traçar uma linha entre o liberalismo e o servilismo, o republicanismo e a autocracia. Sejam quais forem as nuances, aquela claire obscure, aquelas tintas misturadas até que se perca qualquer definição de cor, em que duas cores primárias se confundem, estas cores primárias não ocultam nada, mas formam a grande e única oposição na política, e é possível observá-la tanto nas pessoas quanto nos livros, geralmente à primeira vista. Para onde quer que olhemos no campo da política, encontraremos tais cores. Tudo é por elas preenchido, e atrás delas há só um espaço vazio." 
“O partido liberal é aquele que define o caráter político dos tempos modernos, enquanto o chamado partido servil ainda age, em sua essência, com base no caráter medieval. Daí o liberalismo progredir na própria medida, tal qual o próprio tempo, ou ser inibido na medida em que o passado ainda persiste no presente. Ele corresponde ao protestantismo, na medida em que este protesta contra a Idade Média, e é apenas um novo desenvolvimento do protestantismo em um sentido mundano, assim como o protestantismo foi um liberalismo espiritual. Ele tem seus partidos na classe média educada, enquanto o servilismo encontra o seu no grande mundo e nas massas embrutecidas. Essa classe média funde aos poucos e progressivamente as cristalizações rígidas dos estados medievais. Toda a educação moderna ou proveio do liberalismo, ou serviu-lhe; ela foi a libertação da fé eclesiástica nas autoridades. Toda a literatura é um triunfo do liberalismo, pois seus inimigos devem até mesmo digladiar com suas armas. Todos os estudiosos, todos os poetas o favoreceram, embora ele tenha encontrado seu maior filósofo na figura de Fichte, e seu maior poeta em Schiller."

No capítulo "Filosofia" o senhor Menzel declara-se partidário de Schelling, e no capítulo "Natureza" celebra sua doutrina, como convém. Concordamos com aquilo que ele expressa sobre esse pensador do universal em geral. Lá Görres e Steffens encontram sua apreciação, igualmente, como pensadores schellingianos inferiores. O primeiro recebe a maioria das honras e seu misticismo é elogiado de forma poética até demais. Ainda assim, vemos esse espírito elevado ser cada vez mais sobrestimado do que é rebaixado por razões partidárias. Steffens é descrito como representante do pietismo, e as opiniões que o autor nutre do misticismo e pietismo são, se não também equivocadas, ainda assim profundas, criativas e fabulosas. Não esperamos muita coisa boa do pietismo, embora o senhor Menzel lute para prognosticar o melhor dele. Compartilhamos a opinião de um homem engraçado que audaciosamente afirma: entre cem pietistas, há noventa e nove canalhas e um asno. Não se espera salvação de um beato hipócrita, e nossos tempos de fraqueza não mais revigorar-se-ão com leite de burra. É mais sensato, em vez disso, esperar uma salvação via misticismo. Ainda que em seu aspecto atual possa ser desagradável e perigoso, em seus resultados ele pode atuar como uma cura. O místico, por recolher-se ao mundo onírico de sua intuição interior e aceitar que tem em si a fonte de todo o conhecimento, por escapar da supremacia de toda a autoridade exterior e, dentre os mais ortodoxos, encontrar no fundo de sua alma aquelas inverdades que se põem em contradição com os preceitos da crença positiva, termina por negar a autoridade da Igreja e viver suas convicções de corpo e alma. Um místico da seita dos 
essênios foi aquele rabino que reconheceu a revelação do Pai em si mesmo e salvou o mundo da autoridade cega de leis petrificadas e padres astuciosos. Um místico foi aquele monge alemão que em seu temperamento solitário intuiu a verdade há muito desaparecida da igreja e místicos serão aqueles que nos salvarão dos sermões modernos e restabelecerão uma religião natural, uma onde deuses jubilosos dos bosques e rochedos ressurgirão e também os seres humanos alegrar-se-ão divinamente. A igreja católica sempre sentiu profundamente a periculosidade do misticismo. Daí o fato de, na Idade Média, ela promover mais o estudo de Aristóteles do que o de Platão. Daí também a luta no século passado contra o jansenismo. Se ela se mostra hoje amigável perante homens como Schlegel, Görres, Haller, Müller etc, é porque só os enxerga como guerrilheiros aptos a serem utilizados nestes tempos terríveis de guerra (em que os exércitos da fé se encontram algo fundidos) para então, em tempos de paz, oprimi-los. Levaria muito tempo se quiséssemos demonstrar como também no Oriente o misticismo está destruindo a crença nas autoridades, ou como, por exemplo, seitas derivaram do Sufismo em tempos recentes, seitas cujos conceitos religiosos são da natureza mais sublime.

Não podemos realçar suficientemente a perspicácia com que o senhor Menzel fala do protestantismo e do catolicismo, reconhecendo no primeiro o princípio da estabilidade, e no segundo o princípio da evolução. Nesse sentido ele faz uma observação muito correta no capítulo "Religião".

“O estarrecimento deve opor-se ao movimento, a morte à vida, o ser imutável ao devir eterno. Suficientemente nesse aspecto o protestantismo encontrou seu grandioso significado histórico-mundial. Ele lutou com força jovial, aquela que impele para o desenvolvimento mais elevado e contra o estarrecimento idoso. Ele fez sua lei a partir de uma lei da natureza, e unicamente munido dela será capaz de vencer. Assim, aqueles dentre os protestantes que recaíram em uma outra forma de catalepsia, a ortodoxia, desistiram dos interesses legítimos de sua luta. Eles estacaram e não têm direito de reclamar que os católicos também estacaram. É possível vencer apenas por meio do progresso ininterrupto. O momento em que alguém estaca é tão monocórdico quanto o momento em que os ponteiros de um relógio estacam. Eles só existem para mover-se.”

O tema do protestantismo nos leva a seu mais honrado apologista, Johann Heinrich Voß, quem o senhor Menzel vilifica em toda oportunidade que encontra, com as palavras mais duras e por meio das colocações mais amargas. Não podemos expressar suficientemente 
nossa reprimenda a esse respeito. Quando o autor chama nosso bendito Voß um "fazendeiro chucro baixo-saxão", devemos logo suspeitar que ele se inclina ao partido dos cavaleirinhos e padrecos contra os quais Voß combateu tão bravamente. Esses partidos são poderosos demais para que se possa combatê-los com uma gentil espada galante. Por isso precisamos que um fazendeiro chucro baixo-saxão tenha resgatado a espada dos tempos da Guerra dos Camponeses e descido o cacete com ela. O senhor Menzel talvez nunca sentiu quão profundamente o coração chucro dos camponeses da Baixa Saxônia pode ser machucado pelo aguilhão amigável de uma víbora galante, escorregadia e aristocrática - os deuses certamente preservaram o sr. Menzel de tais sentimentos, caso contrário ele identificaria a aspereza dos escritos de Voß unicamente nos fatos e não nas palavras. Pode ser que Voß, em seu fervor protestante, tenha levado sua iconoclastia um pouco longe demais. Mas considere-se como a igreja agora está filiada à aristocracia em toda a parte e, aqui e ali, é até mesmo subsidiada por ela. A igreja, outrora a dama regente, perante a qual os cavaleiros se curvavam e em prol da qual todo o Oriente competia, essa mesma igreja tornou-se fraca e velha. Agora ela gostaria até de vender seus serviços de criada a esses cavaleiros, e prometer-lhes cantarolar para o 192 povo até ele pegar no sono, de forma que se possa encurralá-lo mais facilmente para tosquiarlhe o pelo.

No capítulo "Arte" amontoam-se a maioria dos disparates contra Voß. O capítulo abarca praticamente toda a segunda parte da obra de Menzel. Não vamos mencionar aqui os juízos feitos sobre nossos contemporâneos mais próximos. A adulação que o autor dedica a Jean Paul faz jus a seu espírito. O mesmo ocorre em seu entusiasmo por Schiller. Também aqui simpatizamos com ele; ainda que não pertençamos àqueles que gostariam de comparar Schiller e Goethe para depreciar o último. Ambos os poetas estão no escalão mais alto. Ambos são grandiosos, admiráveis, extraordinários, e se rendemos reverência a Goethe, é apenas pelo motivo menor de crermos que Goethe seria capaz de criar todo o panteão de Friedrich Schiller, com direito a seus bandoleiros, Piccolominis, Louisas, Marias e virgens, caso tivesse exigido à sua obra a descrição elaborada dos poemas pertencentes a este poeta.

Somos incapazes de expressar com intensidade suficiente nosso espanto ao ver com que dureza e amargura o senhor Menzel refere-se a Goethe. Ele diz muitas coisas verdadeiras, mas que não deveriam ser empregadas contra Goethe. A leitura das páginas que tratam de Goethe, ou melhor, que evitam tratar dele, causou-nos um desconforto repentino tão grande quanto aquele do verão passado em que um banqueiro em Londres, por curiosidade, mostrou- 
nos algumas notas falsas. Não conseguimos deitar fora esses papéis rápido o suficiente por medo de que, repentinamente, fôssemos acusados de falsificadores e levados ao cadafalso para enforcar, sem cerimônia, ao lado do velho Bailly. Só depois de saciar-nos a curiosidade mórbida com as páginas de Menzel, nossa indignação despertou. De forma alguma visamos defender Goethe; cremos que a lição de Menzel de que "Goethe não foi um gênio, apenas um talento" encontrará poucos adeptos, e mesmo esses poucos admitirão que Goethe de vez em quando teve talento para ser genial. Mas mesmo que Menzel tivesse o direito, não lhe seria apropriado expressar seu juízo com tanta dureza. Ainda se trata do rei Goethe, e um resenhista que encosta a faca em tal rei dos poetas deveria ao menos mostrar um mínimo de cortesia, como aquele incisivo juiz inglês que decapitou Carlos I, e que, antes de executar tal ofício crítico, ajoelhou-se perante o delinquente real e pediu-lhe desculpas.

Mas de onde vem essa severidade contra Goethe, que se faz notar aqui e ali mesmo nas mentes mais distintas? Talvez porque Goethe, que não deveria ser nada senão um primus inter pares, terminou como um tirano na república das mentes, e por isso tantas mentes grandiosas encaram-no com um ressentimento oculto. Elas enxergam nele até mesmo um Luís XI, que oprime a alta nobreza intelectual na medida em que ergue o Tiers état intelectual, a amada mediania. Elas veem que ele lisonjeia as corporações dos respectivos estamentos, que envia esplêndidas cartas manuscritas e medalhas a entes queridos fieis, e transforma alguém aclamado em um nobre de patente, um que se julga maior que os verdadeiros grandes da terra, os quais, assim como o próprio rei, receberam sua grandeza pela graça divina, ou, para falar whiggish, pela opinião popular. Afinal de contas, é bem possível que esse seja o caso. Vimos recentemente na tumba principesca de Westminster como os grandes que lá viviam, embora se estapeassem com os reis, permanecem deitados a seu lado na morte - e assim Goethe não pode impedir que aquelas grandes mentes que buscou afastar em vida unam-se a si na morte, e encontrem o leito eterno a seu lado na Westminster da literatura alemã.

A atmosfera de grandeza insatisfeita é contagiosa, e o ar torna-se pegajoso. O princípio da era de Goethe, a ideia da arte, desvanece, uma nova era com novos princípios emerge e - estranho! - como o livro de Menzel nota, ela inicia-se com uma insurreição contra Goethe. Talvez o próprio Goethe sinta que o belo mundo objetivo, instituído por sua palavra e exemplo, esteja necessariamente entrando em colapso, assim como a ideia da arte esteja perdendo sua autoridade gradualmente, e novas mentes frescas, com novas ideias e de uma nova era, estejam sendo expulsas tal qual bárbaros do norte que invadem o sul, e jogarão o 
civilizado culto a Goethe (Goethenthum) sobre uma pilha, para estabelecerem em seu lugar o reino da mais selvagem subjetividade. Daí o esforço para montar uma milícia terrestre goetheana. Em toda a parte há guarnições militares e expedições animadas. Os antigos românticos, os janízaros, servirão de suporte para as forças regulares, deverão virar suas caldeiras, vestir o uniforme de Goethe e fazer exercícios diários. Os recrutas farão bagunça, beberão e gritarão Vivat; os trompetistas assoprarão -

Será que a arte e a antiguidade ${ }^{\mathrm{xx}}$ serão capazes de fazer recuar a natureza e a juventude?

Não podemos deixar de observar expressivamente que não entendemos por Goethenthum as obras de Goethe, aquelas caras criações que talvez ainda sobreviverão quando a língua alemã já estiver há muito morta, e a Alemanha subjugada estiver choramingando em algum dialeto eslavo. Tampouco entendemos por tal expressão o modo de pensar de Goethe, essa flor que prosperará cada vez mais no esterco de nosso tempo, e cujo bem-estar arrefecido deveria também irritar o coração ardente de um entusiasta. Pela palavra Goethenthum referimo-nos acima, ao contrário, às formas goetheanas como as encontramos

194 moldadas por discípulos, e ao apitar frouxo da melodia que o velho assoviava. Mesmo que esse moldar e apitar proporcione ao velho alegria, eles nos causam lamento. $\mathrm{O}$ velho, quão manso e dócil ele se tornou! Como ele se aperfeiçoou! O que diria um nicolaísta que o conheceu naqueles anos selvagens em que escreveu o mormacento Werther e o Götz da mão de ferro! Quão amaneirado ele se tornou, quão funesta lhe é agora toda a crueza, com que desagrado ele não se comove quando é lembrado dos tempos antigos, de xenialidade ${ }^{\mathrm{xxi}}$ e motins celestiais, ou quando outros, seguindo seus antigos passos, extravasam a mesma presunção de sua adolescência titânica! Nesse sentido, um estrangeiro comparou nosso Goethe muito apropriadamente a um chefe bandoleiro que abandonou seu ofício e levou uma vida burguesa honrosa sob os honorários de uma cidadezinha provinciana, até que inventa de encher-se de todas as virtudes filisteias mais baixas e cai no constrangimento mais doloroso quando, casualmente, um companheiro de bosques da Calábria o encontra e quer exigir o antigo companheirismo.

- Heinrich Heine.

\section{REFERÊNCIAS BIBLIOGRÁFICAS}

BÜTTNER, Frank. Der Streit um die ,Neudeutsche Religios-Patriotische Kunst ${ }^{\star}$. Aurora, n. 43 (1983), p. 55-76. 
DREWITZ, Ingeborg. „Wir müssen etwas tun, was Ersatz ist für das, was wir tun könnten. Die Autoren des Jungen Deutschland und Goethe“. In: BUCH, Hans Christoph. Literaturmagazin 2. Von Goethe lernen? Fragen der Klassikrezeption. Hamburg: Rowohlt Taschenbuch Verlag, 1974, p. 113-119.

FRANK, Hilmar. „Anzeigen, Kritiken, Rezensionen zur bildenden Kunst“. In: DAHNKE, Hans-Dietrich \& OTTO, Regine. Goethe Handbuch, Bd. 3. Stuttgart / Weimar: J. B. Metzler, 2004, p. 640-654.

GUTZKOW, J. Karl. Wolfgang Menzel und das „Junge Deutschland“. Neue Freie Presse. Wien. Nr. 3153, 4. Juni 1873, p. 1-3.

HABERMAS, Jürgen. Heinrich Heine e o papel do intelectual na Alemanha. Tradução de Priscila Figueiredo e Luiz Repa. Cadernos de Filosofia Alemã, n. 3, p. 79-105, 1997.

HÄNTZSCHEL, Günter. Das Ende der Kunstperiode? Heinrich Heine und Goethe. (2003). In: Goethezeitportal. Disponível em: <http://www.goethezeitportal.de/db/wiss/epoche/haentzschel_kunstperiode.pdf >. Acesso em: $11 / 01 / 2017)$.

HEINE, Heinrich. Die deutsche Literatur von Wolfgang Menzel. 2 Theile. Stuttgart, bei Gebrüder Frankh. 1828. Neue allgemeine politische Annalen. Bd. 27, 1828, Heft 3, p. 284298. Versão facsímile disponível em <https://www.unidue.de/lyriktheorie/scans/1828_heine.pdf >. Acesso: 11/01/2017.

Die romantische Schule. Hamburg: Hoffmann und Campe, 1836. Versão facsímile disponível em <https://books.google.com.br/books?id=VqkDAAAAQAAJ>. Último acesso: 14/01/2017.

Säkularausgabe. Werke, Briefwechsel, Lebenszeugnisse. Band 20: Briefe 1815-1831. Berlin: Akademie-Verlag, 1970.

Contribuições à História da Religião e Filosofia na Alemanha. Tradução Márcio Suzuki. São Paulo: Iluminuras, 1991.

HOHENDAHL, Peter Uwe. "The Epoch of Liberalism, 1820-1870". In: HOHENDAHL, Peter Uwe (org.). A History of German Literary Criticism: 1730-1980. Lincoln / London: University of Nebraska Press, 1988, p. 179-276.

HÖHN, Gerhad. Heine Handbuch. Zeit, Person, Werk. Stuttgart/Weimar: Verlag J.B. Metzler, 2004.

IMMERMANN, Karl. Werke. Herausgegeben von Benno von Wiese, Band 1, Frankfurt a.M. / Wiesbaden: Athenäum, 1971.

KOPELEW, Lew. Ein Dichter kam vom Rhein. Heinrich Heines Leben und Leiden. Berlin: Severin und Siedler, 1981. 
LAUSTER, Martina. Vom Körper der Kunst. Goethe und Schiller im Urteil Heines, Börnes, Wienbargs und Gutzkows (1828-1840). Goethe Jahrbuch, Band 122. Göttingen: Wallstein Verlag, 2005, p. 187-201.

OROSZ, Magdolna. Heine und die deutsche Romantik. Arbeiten zur deutschen Philologie, XXVI, 2002, p. 105-122.

SAFRANSKI, Rüdiger. Romantismo: uma questão alemã. Tradução Rita Rios. São Paulo: Estação Liberdade, 2010.

VERBOT DER SCHRIFTEN DES »JUNGEN DEUTSCHLAND « vom 10. Dezember 1835 (31. Sitzung der Bundesversammlung, 1835). Disponível em: <http://www.heinrich-heinedenkmal.de/dokumente/beschluss.shtml>. Acesso em: 14/01/2017.

RECEBIDO EM: 26 de maio de 2017

ACEITO EM: 22 de setembro de 2017

PUBLICADO EM: novembro de 2017

* Felipe Vale da Silva. Doutor (2016) e Mestre (2012) em Letras - Língua e Literatura Alemã (2016) pela Universidade de São Paulo (USP). Graduado em Letras (2006) pela mesma universidade. São Paulo, São Paulo, Brasil.

Lattes: http://lattes.cnpq.br/5226574394994548 E-mail: felipe.vale.silva@gmx.com

${ }^{\mathrm{i}}$ Esta e as traduções conseguintes serão minhas. No original (IMMERMANN, 1971, p. 421) consta: „Jetzo ist die Zeit der Kleinen!/Große Taten kleiner Leute/Will die Welt, [...]".

ii Safranski (2010, p. 220) resume bem os debates desta época de tumultos: "Os 'partidos' caem uns sobre os outros. Herwegh condena Freiligrath. Engels faz campanha contra Heine. Heine contra Börne e vice-versa. Feuerbach critica Strauß, Bauer critica Feuerbach. Stirner quer ser melhor que todos, mas então vem Marx, que os coloca todos no mesmo saco: 'a ideologia alemã'”.

${ }^{i i i}$ Heine comenta as atividades políticas da juventude de Menzel em carta a Varnhagen de 28/11/1827 (HEINE, 1970, p. 307).

iv „Hoher Bundestag in Frankfurt am Main hatte 1834 den Kopf voll von nichts als Giovine Italia und Carbonari und Vendetta und Munkacs und Spielberg, und Andere wieder dachten bei der Entdeckung, die der Bundestag auch in einer literarischen Giovine Alemagna gemacht haben wollte, [...] kurz, man wollte für bestimmt und fest annehmen, diese fünf Schriftsteller, denen sich als sechster Freiwilliger noch Gustav Kühne anschlo $\beta$, hätten das Programm, das ihnen Wolfgang Menzel andichtete: Franzosenthum, Fleisches-Emancipation, Atheismus u. s. w., unter sich in einer nächtlichen Sitzung abgesprochen“.

${ }^{v}$ Para um tratamento mais extenso do processo, ver Lauster (2005, p. 197) e Kopelew (1981, p. 264 et seq). O documento oficial de proibição da Jovem Alemanha, lavrado a 10 de dezembro de 1835, foi resgatado por Wolfgang Fricke e disponibilizado em linha (ver VERBOT DER SCHRIFTEN DES »JUNGEN DEUTSCHLAND «, 1835 nas referências bibliográficas).

vi Trechos citados a partir de Heine (1828, p. 287): „,Menzel sucht viel eher das Verhältniß des Lebens zu den Büchern aufzufassen, einen Organismus in der Schriftwelt zu entdecken [...] [Wir erkennen bei Menzel] ein Streben nach Wissenschaftlichkeit, welches ebenfalls eine Tendenz unserer neuesten Zeit ist, eine jener Tendenzen, wodurch sie sich von der früheren Kunstperiode unterscheidet.“

vii „, [Goethes Tod und die Pariser Revolution begrüßte man als] Symbole eines neuen Anfangs in der Literatur, von dem man sich zeitgemäße Demokratisierung in Thematik und Ästhetik wie auch Freiheit in der Öffentlichkeit, freie Meinungsäußerung, Pressefreiheit, Abschaffung der Zensur versprach " (HÄNTZSCHEL, 2003, p. 2).

viii „, [...] jetzt gilt es die höchsten Interessen des Lebens selbst, die R e vo l u z i o n tritt ein in die Literatur [...] “ (carta a Varnhagen von Ense, 04/02/1830; HEINE, 1970, p. 385). 
ix „, [...] der Mittelpunkt des Menzelschen Buches ist nicht mehr die Idee der Kunst“ (HEINE, 1828, p. 287).

${ }^{x}$ Ver Orosz, 2002, p. 117. Häntzschel (2003, p. 8) chega a identificar no método heineano um gérmen da estética da recepção desenvolvida com rigor somente no século XX.

xi A primeira obra mencionada foi traduzida para o português por Márcio Suzuki (ver HEINE, 1991 nas referências bibliográficas), ao passo que Die romantische Schule ainda aguarda tradução.

xii O mesmo ocorre em uma obra recente como a de Safranski (2010); ver comentários em Orosz, 2002, p. 119.

xiii "Young Germany was the most decided and outspoken opponent of previous Romanticisms, but in an essentially romantic form [...] it wanted to close the gap between literature and life, [...] but in order to do this it made use of exclusively literary means."

xiv "The crisis of Goethean and Romantic paradigma inheres in their inability to seize the dialectic moment of history in the essential sense of the word dialectic, that is, as a dialogue with the present [...]" (SEYHAN apud OROSZ, 2002, p. 117, nota 34)

xv „Wir können nicht umhin, ausdrücklich zu bemerken, daß wir unter "Goethenthum" nicht Goethes Werke verstehen, nicht jene theuern Schöpfungen, die vielleicht noch leben werden, wenn längst die deutsche Sprache schon gestorben ist, [...]mit dem Wort "Goethenthum" deuteten wir oben vielmehr auf Goethesche Formen, wie wir sie bei der blöden Jüngerschaar nachgeknetet finden, und auf das matte Nachpiepsen jener Weisen, die der Alte gepfiffen."

xvi Ver comentários sobre o debate em Frank (2004, p. 647-8) e Büttner (1983, p. 56).

xvii „Mit diesem Artikel machte Goethe gleichsam seinen 18ten Brümaire in der deutschen Literatur“.

xviii "As soon as the aesthetic sphere appears to be removed [... from] the realms of politics and morality, it becomes impossible to assign to art any specific purpose beyond self-referentiality."

xix O termo "juiz" empregado na citação refere-se a leitores de espírito crítico (Nota do tradutor).

${ }^{x x}$ Referência à revista de Goethe e Meyer de título Sobre Arte e Antiguidade nas regiões do Reno e do Meno (Nota do tradutor).

xxi Aqui não se trata de um erro de digitação, mas um trocadilho com os Xenien, epigramas lançados por Goethe e Schiller a partir de 1797 com o intuito de satirizar figuras públicas alemãs (Nota do tradutor). 